\title{
Die kwalitatiewe onderhoud as data-insamelingstegniek: sterk en swak punte
}

\author{
Priscilla Botha
}

\begin{abstract}
SUMMARY
In qualitative research, in-depth interviewing is an important research tool for data gathering, with the researcher as the measuring instrument. The qualitative interview is flexible and dynamic and has been referred to as nondirective, unstructured, nonstandardised and open-ended. Taylor and Bogdan (1984:77) define the qualitative interview as repeated face-to-face encounters between the researcher and informants directed toward understanding informants' perspectives on their lives, experiences, or situations as expressed in their own words. Some authors stress the role of talk as well as various ways of communication during interviewing.
\end{abstract}

Although the qualitative interview - like other datagathering techniques - has its strengths and weaknesses, it is argued that this method is a tool and that its utility depends largely on its pertinence to the research question. It is also argued that its strengths and weaknesses are functions of the competencies and skills of the researcher using this tool to elicit the required information.

The following aspects are discussed:

- Qualitative interviews are particularly suitable for studying people's understanding of their world, for describing their experiences and selfunderstanding, and for clarifying and elaborating their perspectives of their world (Seidman, 1998:3-4). In gathering such information, the researcher should be interested in people and the subjects should be studied in their own setting to discover the meanings the subjects attach to their behaviour. Data gathering presupposes a certain familiarity with the subjects' culture.

- The very virtue of a qualitative interview is its openness. Apart from certain standard choices, this openness and the absence of a prescribed set of rules create a variety of opportunities for the researcher. These opportunities demand skills, knowledge and intuition from the interviewer. It has been said that interviewing is a craft that is closer to art than to standardised social science methods (Kvale, 1996:84, 105; Seidman, 1998:9, 11).

- Qualitative research interviews could serve as an auxiliary method in conjunction with other methods (Walker, 1985:4). This process of triangulation enhances the validity of the research (Smaling, 1992:319).

- Qualitative interviewing is both a research technique and a social relationship that has to be nurtured. An intersubjective understanding between the interviewer and the interviewee depends upon creating an 'I - Thou' relationship (Seidman, 1998:79). 'Thou' is someone close to the interviewer. There are mutual respect and sensitivity for differences in social class, ethnicity and gender. These aspects could stand in the way of crafting a good relationship. Feminists have strong negative feelings about a hierarchical relationship between the researcher and participants as well as the exploitation of interviewees. It should be a give-and-take relationship (Oakley, 1981:31-41).

- Data gathering by means of qualitative interviewing is time-consuming (Jones, 1985:46-47) and requires considerable expertise in both subject matter and human interaction (Kvale, 1996:103). It is therefore often difficult, and is by implication expensive.

- It cannot be assumed that everyone is equally capable of expressing his or her thoughts on and reasons for certain behaviours (Seidman, 1998:3-4). Researchers should be encultured in aspects relevant to the research. It is also known that expressed attitudes are not necessarily good predictors of actual behaviour (Baron \& Byrne, 1996:140-141). Language could also be a barrier in cross-cultural studies (Fontana \& Frey, 19367; Stewart, 1998:25).

- The objectivity of knowledge acquired by way of qualitative interviewing is discussed with specific regard to different concepts of objectivity: as freedom from bias, as intersubjective knowledge, and as reflective of the nature of the object (Kvale, 1992:64-66; Smaling, 1989:162).

- Prof Priscilla Botha

Departement Verbruikerswetenskap Universiteit van Pretoria 


\section{INLEIDING}

Kwalitatiewe navorsing word paradigmaties interpretatief bespreek, met ' $n$ ontologiese siening van die mens as unieke wese en interpreteerder en/of kommunikeerder van sy leefwêreld (Smaling, 1994)*. In aansluiting hierby kan die mens se sosiale wêreld (onder meer vanuit die fenomenologie) ontleed, vertolk en begryp word (Kruger, 1985:145). Kruger skryf dat ' $n$ fenomenologiese benadering tot navorsing gekenmerk word deur openheid vir wat betekenisvol is om die verskynsel wat bestudeer word behoorlik te kan begryp (1985:154). Seidman (1998:3) stel dit nog eenvoudiger, naamlik dat die grondslag van kwalitatiewe onderhoude is om die ervarings van ander en die betekenis wat hulle daaraan heg te begryp. Lofland in Fielding (1993:137) meen dat die doel van ongestruktureerde onderhoude ... (is) to elicit rich, detailed materials ... to find out what kinds of things are happening rather than to determine the frequency of predetermined kinds of things that the researcher already believes can happen.

In aansluiting by Kruger aanvaar Taylor en Bogdan (1984) dat die kwalitatiewe onderhoud besonder plooibaar en dinamies is. Hulle som die kenmerke daarvan op as nie-voorskriftelik, ongestruktureerd en ongestandardiseer met ' $\mathrm{n}$ redelike oop agenda, en omskryf ' $n$ kwalitatiewe onderhoud as ... repeated face-to-face encounters between the researcher and informants directed toward understanding informants' perspectives on their lives, experiences, or situations as expressed in their own words (Taylor \& Bogdan, 1984:77).

Diepte-onderhoude is een van die belangrikste datainsamelingstegnieke in kwalitatiewe navorsing (Jones, 1985:45; Hunt \& Eadie, 1987:10; Fontana \& Frey, 1994:361). Selfs in die geval van deelnemende waarneming - ' $n$ ander belangrike data-insamelingstegniek in kwalitatiewe navorsing - is informele diepte-onderhoude ' $n$ betekenisvolle aspek van kwalitatiewe navorsing.

Diepte-onderhoudvoering in kwalitatiewe navorsing onderskei sigself van onderhoude in ' $n$ meer

\footnotetext{
* Sosiaal wetenskaplike navorsing word gewoonlik paradigmaties gekenmerk as empiries-analities of interpretatief of krities. Hierdie drie paradigmas stem vir sekere teoretici ook respektiewelik ooreen met die volgende ontologiese siening of mensbeskouing: die mens as meganisme, organisme of robot; die mens as ' $n$ individu, interpreteerder of kommunikeerder; die mens as emansipeerder. Verder kan elk ook onderskei word deur die aard van wetenskaplike kennis en hoe dit bedryf moet word (die metodes en tegnieke). Ander teoretici onderskei tussen kwantitatiewe (empiries-analities), kwalitatiewe (interpretatief) en deelnemende of aksieparadigmas (Mouton, 1996:37). Hierdie onderskeid is egter metodologies sonder verwysing na ander dimensies. ' $n$ Verdere tipe onderskeid is respektiewelik positivisties, interpretivisties en realisties. Daar is egter min ooreenstemming oor die aantal en soorte paradigmas in sosiaalwetenskaplike navorsing. (Lees Smaling, 1992 en 1994 vir 'n goeie uiteensetting van hierdie debat.)
}

positivistiese navorsingstradisie dat laasgenoemde kwantitatief meet en gestruktureerd is. In ' $n$ kwalitatiewe onderhoud is die onderhoudvoerder* die meetinstrument en die onderhoud is nie in dieselfde mate gestruktureerd nie (Jones, 1985:53). Ten einde die dinamiek van onderhoudvoering te kan beskryf, moet die kwalitatiewe onderhoud as ' $n$ interaksieproses tussen die onderhoudvoerder en die subjek beskou word (Oakley, 1981:44).

Kwalitatiewe onderhoude, soos ander data-insamelingstegnieke, insluitend kwantitatiewe metodes, het sterk en swak punte. Hierdie artikel voer, in ooreenstemming met Seidman (1998:5) se argument, aan dat die keuse van 'n navorsingsmetode en die kundigheid van die navorser grotendeels bepaal of die verlangde inligting verkry sal word. Die navorsingsvraag/-probleem is bepalend ten opsigte van die metode (Ackroyd \& Hughes, 1981:30). Die metode en die probleem moet dus bymekaar aanpas (Mouton, 1996:37), en die navorser moet oor die nodige belangstelling, aanleg, noukeurigheid en kreatiwiteit beskik om die bepaalde metode suksesvol te kan toepas. Kvale (1996:69) skryf soos volg hieroor asook oor die dualisme wat dikwels tussen metodes bestaan wat met kwantitatiewe en kwlitatiewe navorsing verband hou: ... (these) are tools, and their utility depends on their power to bear upon the research questions asked. As tools they require different competencies, with differences among researchers in their abilities to and interests in carrying out quantitative computations or conducting linguistic or empathic analysis of qualitative data.

Die volgende aspekte rondom die sterk en swak punte van kwalitatiewe onderhoude word in hierdie artikel beredeneer:

- Kwalitatiewe onderhoude is geskik om inligting oor menslike ervarings en gedrag te bekom.

- Dit is grotendeels ongestruktureerd om die deelnemers in perspektief te beskou.

- Kwaltitatiewe onderhoude kan 'n sensitiwiteit vir deelnemers en hulle leefwêreld openbaar.

- Dit kan met vrug saam met ander data-insamelingstegnieke gebruik word om vir die swak punte van ' $n$ bepaalde tegniek of metode te kompenseer.

- Data-insameling by wyse van kwaltitatiewe onderhoude en die daaropvolgende data-analise is dikwels tydrowend, moeilik en duur.

- Die aanname dat taal 'n goeie indikator van 'n mens se denke en gedrag is, hou nie noodwendig steek nie.

- Kwaltitatiewe onderhoude kan op wetenskaplik-

\footnotetext{
* In hierdie skrywe word die gewoonte gehandhaaf om die 'manlike' vorm as onsydig te beskou.
} 
heid aanspraak maak aangesien dit vakmanskap vereis.

\section{DIE KWALITATIEWE ONDERHOUD IS GESKIK OM INLIGTING OOR MENSLIKE ERVARING EN GEDRAG TE ONTGIN}

Kwalitatiewe onderhoude as 'n data-insamelingstegniek is nie noodwendig geskik om enige navorsingsvraag of -probleem te ondersoek nie. Die kwalitatiewe onderhoud gaan volgens Jones (1985:46), na aanleiding van teoretici soos Thomas en Thomas, Kelley asook Berger en Luckman, van die veronderstelling uit dat mense die betekenis en belang van hul leefwêreld en die realiteit daarvan vir hulself skep en konstrueer. Die wyse waarop en die rede waarom mense hulle eie realiteit skep, verduidelik Jones (1985:46) soos volg: They do so by bringing to bear upon events a complex personal framework of beliefs and values, which they have developed over their lives to categorise, characterise, explain and predict the events in their worlds. It is a framework which, in a social world, is shared in some parts with some others but one in which the points of commonality cannot be assumed as self-evidently, non-problematically, 'given'. In order to understand why (eie onderstreping) persons act as they do, we need to understand the meaning and significance they give to their actions.

Uit bogenoemde kan dus afgelei word dat die kwalitatiewe onderhoud besonder geskik is om die betekenis wat mense aan hul leefwêreld heg asook hulle ervarings en selfbegrip te ontgin. Dit is ook geskik om duidelikheid oor mense se lewensperspektiewe en -verwagtings te verkry (Kruger, 1985:146; Kvale, 1996:105; Mouton, 1996:168), en om fynere besonderhede te bepaal (Fielding, 1993:138).

Om hierdie tipe inligting te ontgin, moet die onderhoudvoerder ' $n$ intense belangstelling in mense hê (Seidman, 1998:3) om hul dieper belewenisse en die betekenis wat hulle daaraan heg te kan begryp. Dit is ook wenslik dat die onderhoudvoerder die subjekte in hul eie omgewing of konteks bestudeer (Kruger, 1985:146; Neuman, 2000:345) - selfs terwyl die respondent met sy dagtaak besig is (Oakley, 1981:49). Wat die navorser waarneem, kan nooit los van die waarnemingskonteks beskou word nie. Dit skep die geleentheid om die subjektiewe betekenis wat aan eie gedrag geheg word te begryp (Seidman, 1998:3-4). Die laasgenoemde aspek veronderstel dus ' $n$ fyn waarnemingsvermoë (Stewart, 1998:17). Al die genoemde aspekte help die onderhoudvoerder om ' $\mathrm{n}$ binnestaanderperspektief van die subjekte te ontwikkel.

Die onderhoudvoerder moet 'n sekere voorkennis van die kultuur van die respondent hê (Kvale, 1996:96). Daarom behoort die onderhoudvoerder genoeg tyd in die tuisomgewing en teenwoordigheid van die respondent deur te bring voordat die werklike onderhoude begin. Op hierdie wyse kan die taalgebruik en sekere segswyses van die subjekte waargeneem word, asook hoe hulle hul daaglikse take verrig (Oakley,
1981:57). Dit is ook moontlik om rolle en (mag)strukture binne die groep waar te neem om sodoende ' $n$ goeie aanvoeling te kry vir wat vir die respondente belangrik is en waaroor hulle graag sal wil praat. So kan ' $n$ goeie verhouding tussen die onderhoudvoerder en die respondente opgebou word - ' $n$ vereiste om mense se ervarings en belewenisse te kan begryp (Fontana \& Frey, 1994:367). Stewart $(1998: 15,17)$ praat van 'n empatiese begrip wat nodig is om geloofwaardige data te kan ontgin.

Dit is dus duidelik dat die kwalitatiewe onderhoud geskik is en by implikasie as ' $n$ sterkpunt gesien kan word om die betekenis wat mense aan ervarings in hul leefwêreld heg te ondersoek.

\section{KWALITATIEWE ONDERHOUDE IS ONGESTRUK- TUREER EN PLOOIBAAR WAT DIT TEGELYK 'N KUNS EN 'N WETENSKAP MAAK}

Baie outeurs, byvoorbeeld Walker (1985) en Stewart (1998), is dit eens dat daar min of geen standaardprosedures of -tegnieke vir ongestruktureede onderhoude bestaan nie. Daar bestaan egter wel standaardkeuses wat tydens die navorsingsproses gemaak moet word. Hierdie keuses behels onder meer die aantal onderhoude, of 'n bandopnemer gebruik moet/kan word, of die onderhoude getranskribeer moet word, watter tipe data-analise toepaslik sal wees, of die respondente 'n kans gegun moet word om die navorser se interpretasie van die onderhoude te lees om vas te stel of hulle daarmee saamstem al dan nie, en so meer.

Benewens die genoemde standaardkeuses wat gemaak moet word, is daar min beperkings en staan dit die navorser vry om die onderhoude op intuïsie en kundige aanvoeling te voer. Walcott (1994:39) skryf dat ... we (qualitative sholars) are all self styled researchers. Hierdie werkswyse tipeer ook wat Mouton (1990:166) subjektiverend (teenoor objektiverend) noem, met ander woorde die navorsing moet nie wat "ek" weet bevestig nie, maar die "stories" van die subjekte (Rubin \& Rubin, 1996:6). Stewart (1998:3) stem saam dat kwalitatiewe navorsingspraktyke - wat diepte-onderhoude insluit - in die ware sin van die woord idiosinkraties is en dat dit dus belangriker is om die uitkomste van die gekose metode te evalueer as die metode self.

Ten spyte van die groot aantal skrywers wat die idiosinkratiese aard van kwalitatiewe onderhoude beklemtoon, is daar ander (soos Kvale (1996), Spradley (1979) en Seidman (1998)) wat vir veral vir die oningewyde aanduidings wil gee oor hoe sulke onderhoude in die breë beplan kan word. Seidman (1998:11) skryf byvoorbeeld dat minstens drie onderhoude beplan moet word om die onderwerp en ondervinding vir beide partye te peil en in konteks te plaas. Die eerste onderhoud kan daarop gemik wees om formele aspekte rondom die navorser, die navorsingsonderwerp en die doel met die navorsing te kommunikeer en om die subjek se ervarings in konteks te plaas. Tydens die tweede onderhoud kan die subjek die detail van sy of 
haar ervarings binne die konteks waarin dit plaas-gevind het, rekonstrueer, en in die derde onderhoud kan die subjekte gevra word om na te dink oor die betekenis wat hierdie ervarings vir hulle het.

Die onderhoudvoerder moet sensitief en kundig wees om te kan "hoor" wat die subjek meedeel. Hy of sy moet die subjek met die nodige behendigheid en aanvoeling kan aanmoedig om die verlangde inligting eerlik mee te deel. Die kwaliteit en die tipe inligting wat verkry word, hang dus in 'n groot mate af van die kundigheid, vaardigheid en aanvoeling van die onderhoudvoerder. Goeie onderhoudvoering vereis dus vakkennis en bowenal kundigheid van en begrip vir menslike interaksie (Oakley, 1981:58; Taylor \& Bogdan, 1984:77).

Dit is juis op grond van hierdie vrye hand in onderhoudvoering dat skrywers sê dat die kwalitatiewe onderhoud tegelyk ' $n$ kuns en 'n wetenskap is. Kvale $(1996: 84)$ stel dat ... interviewing is a craft that is closer to art than to standardized social science methods.

Die Afrikaanse term "kunsvakman" vir craft artist skyn paslik te wees as dit by kwalitatiewe onderhoudvoering kom omdat beide aspekte (kuns en vakman) belangrike komponente daarvan is. Die onderhoudvoerder moet netjies tussen all methods en no methods of tussen oordrewe formalisme en naïewe spontaneïteit kan stuur. Kvale (1996:105) stel dat daar 'n klemverskuiwing in kwalitatiewe onderhoude is - van die metode na die persoon/navorser en/of subjek, dit is van die wetenskap na die kuns - en dat goeie navorsingsmetodiek deur ervaring aangeleer word. Daarom is reëls van minder belang en word eerder op die goeie oordeel van ' $n$ ervare navorser staatgemaak. Die geslaagdheid van 'n onderhoud - met ander woorde die kragtigheid van die meetinstrument hang dus direk van die onderhoudvoerder se vakkennis en insig in menslike interaksie asook van sy of haar sensitiwiteit vir en empatie met die subjekte af.

In die lig van al die bogenoemde "voorbehoude" kan kwalitatiewe onderhoudvoering 'n kragtige tegniek wees om kontekstueel geloofwaardige inligting oor ' $n$ bepaalde domeinverskynsel te ontgin.

\section{SENSITIWITEIT VIR SUBJEKTE EN HULLE LEEFWêRELD}

Die besondere interaksionele aard van kwalitatiewe onderhoudvoering - veral vanuit 'n humanistiese oogpunt - en die relatiewe lang verbintenis met die subjekte maak sensitiewe hantering moontlik. Seidman (1998:79) praat van 'n I/Thou-verhouding tussen persone wat na aan mekaar staan. Aspekte soos die geslag, etnisiteit, geloof en ander biografiese eienskappe van beide partye asook die onderwerp van die gesprek in ' $n$ bepaalde onderhoudsituasie kan dus makliker beheer word omdat daar wedersydse respek en sensitiwiteit teenoor mekaar bestaan (Hammersley \& Atkinson, 1995:92-98).
Denzin (1989:116) het onder meer opgemerk dat gender filters knowledge - met ander woorde die geslag van die onderhoudvoerder en die subjek maak ' $n$ verskil in die interaksiesituasie. Dit is veral feministe soos Oakley (1981:31-41), Devault (1990:110) en Fontana en Frey (1994:369-70) wat sterk standpunt hieroor inneem. Hulle het dit teen die tradisionele patriargiese en positivistiese benadering wat voorskriftelik van aard is, en byvoorbeeld dat feministe onderhoude met vroue moet voer omdat $A$ feminist interviewing women is by definition both 'inside' the culture and participating in that which she is observing (Oakley, 1981:57). Hierdie benadering verseker ' $n$ breër spektrum response en beter insig in en begrip vir die subjekte se leefwêreld.

Verder bepleit die bogenoemde navorsers ' $n$ vriendskapsverhouding tussen die onderhoudvoerder en die deelnemer* (teenoor die afsydige en onbetrokke verhouding wat die positiviste voorhou) om onder meer uitbuiting van deelnemers te bekamp en eerder ' $n$ gee-en-neem-verhouding te vestig. Oakley (1981:49) stel dat no intimacy without reciprocity moontlik is nie. Hierdie wedersydse vriendskapsverhouding is veral belangrik wanneer onderhoude oor 'n lang periode strek. Deur byvoorbeeld te antwoord op vrae van die deelnemers en eie gevoelens en ervarings met die subjekte te deel, "vergoed" Oakley vir die tyd en gasvryheid wat sy van subjekte ontvang het tydens haar navorsing oor moederskap. Hierdie tipe verhouding bring groter persoonlike tevredenheid vir beide partye. So word rapport bevorder, wat tot groter verantwoordelikheid vir die navorsing lei.

Sensitiwiteit teenoor die deelnemers word moontlik as die onderhoudvoerder die subjekte op 'n gelyke vlak kan ontmoet. Dit is makliker as die sosiale afstand nie te groot is nie, as beide van dieselfde geslag is, en as sosialisering en kritiese lewenservarings ooreenkomste toon (Oakley, 1981:41; Fontana \& Frey, 1994:369). Onderhoudvoering wat sensitief teenoor die deelnemers is, genereer ' $n$ beter kans op betroubare inligting (Oakley, 1981:44).

\section{KWALITATIEWE ONDERHOUDE EN ANDER DATA- INSAMELINGSTEGNIEKE KAN MEKAAR WEDER- SYDS VERSTERK}

Kwalitatiewe onderhoude kan met vrug saam met ander data-insamelingstegnieke gebruik word om veral kruisvalidasie te bewerkstellig (Walker, 1985:4; Smaling, 1994):

- Onderhoude kan as basis gebruik word om vraelyste of skale te konstrueer (Seidman, 1998:98), veral as die domeinverskynsel vir die navorser onbekend is (Smaling, 1994). Stellings in die onder-

\footnotetext{
* Die term "deelnemer" (participant) word deur die feministe verkies omdat "respondent" ' $n$ hiërargiese vehouding suggereer en 'n passiewe rol impliseer teenoor die interaktiewe rol wat die fenomenoloë bepleit. Subjekte en deelnemers word dus vir beide interviewees gebruik.
} 
houde kan as vrae of indikatore vir die kwantitatiewe meetinstrumente gebruik word wat dan op 'n ander, soortglyke groep toegepas kan word. By onderhoude wat heelwat minder subjekte betrek, is die doel om diepgaande kennis van of begrip vir die belewenisse en gedrag van die subjekte te verkry. Daarenteen is die doel met vraelyste gewoonlik om verteenwoordigende en veralgemeenbare kennis te bekom (Kvale, 1996:67; Mouton, 1996:38). Kvale (1996:93-94) verwys na haar eie navorsing en dié van Hvolbol en Kristensen waarvoor beide navorsingstyle en -tegnieke gebruik is om inligting oor die puntetoekenning vir toetse en projekte in hoërskoolvakke in te win. Die onderhoude het interessante oortuigings van die leerlinge oor puntetoekenning aan die lig gebring, en uitgewys watter tipe gedrag van hulle kant aanleiding tot goeie punte kan gee. Die vraelyste het weer die voorkoms en omvang van hierdie oortuigings uitgewys. Die onderhoudvoerder kon selfs verder gegaan het deur uitsonderlike of interessante response op geskeduleerde vrae op te volg om die navorsingsbevindinge met konkrete voorbeelde toe te lig. Op hierdie wyse kompenseer die sterk punte van een styl vir die swak punte van 'n ander.

- In studies waarin die navorser die rol van deelnemende waarnemer aanneem, speel informele onderhoudvoering (of selfs van ' $n$ meer formele aard) ' $n$ baie groot rol in die insameling van data. Daar is veral geleentheid vir spontane onderhoude tydens veldstudies (Hammersley \& Atkinson, 1995:156). Etnograwe heg meer waarde aan inligting wat op hierdie manier verkry is, in teenstelling met inligting wat tydens ' $n$ formele of voorafgereëlde onderhoud verkry word (solicited versus unsolicited accounts) (Hammersley \& Atkinson, 1995:129,139).

- In aansluiting by die eerste punt kan die subjekte vir onderhoude op grond van uitsonderlike response gekies word om aspekte wat buite die normale/ wetmatige val, toe te lig of te verklaar. Vir kwalitatiewe navorsers is uitsonderlike gevalle van belang. Hulle gebruik juis hierdie inligting in die data-ontleding om ' $n$ teorie te toets of suiwerder te formuleer (Stewart, 1998:17).

\section{DATA-INSAMELING DEUR KWALITATIEWE ONDERHOUDE IS MOEILIK, TYDROWEND EN DUUR}

Een van die kenmerke van kwalitatiewe onderhoude wat vir sommige navorsers aantreklik is, is die ongestruktureerde aard en oop agenda daarvan. Dit maak hierdie tipe onderhoud egter tegelykertyd ' $n$ moeilike tegniek om te beheers. Wat die subjek betref, moet die diepte-onderhoud ongestoord voortgaan sonder dat die onderhoudvoerder die gesprek te veel onderbreek of voortydig in ' $n$ ander rigting stuur. Dit kan gebeur wanneer die onderhoudvoerder brand om sy of haar voorafbeplande vrae te vra. Op hierdie wyse kan inligting by die onderhoudvoerder verbyglip, en die kans is goed dat subjekte gefrustreerd raak wanneer hulle nie toegelaat word om dit wat vir hulle belangrik is ten volle mee te deel nie (Jones, 1985:4647). Onderhoudvoerders moet dus ' $n$ fyn aanvoeling kweek om te weet wanneer die gesprek onderbreek kan word. Hulle moet vroegtydig besef wanneer die subjek ' $n$ aantal temas van belang aansny. Dit verg sensitiewe aanvoeling om die subjek te laat weet dat wat hy of sy oordra wel belangrik is, maar dat verskillende temas een vir een hanteer moet word, en sommige temas vir latere onderhoude moet oorstaan. Bostaande bevestig weer eens dat kwalitatiewe onderhoude ' $n$ tegniek vir die kunsvakman is.

Daar is reeds genoem dat dit wenslik is om tyd in die navorsingsomgewing deur te bring (Stebbins, 1998:96) voordat die werklike studie 'n aanvang neem. Jones (1985:46), Kvale (1996:103), Seidman (1998:11) en Stewart $(1998: 17,20)$ beklemtoon dat minder maar diepgaande gesprekke gevoer moet word, maar dit neem baie tyd in beslag. Kwalitatiewe navorsers moet goed nadink oor die data wat tydens verskillende onderhoude ingesamel word. Walcott (1994:37) stel dit soos volg: ... one does need to think about data; this thinking cannot be speeded up.

Daar word in die meeste kwalitatiewe studies 'n oorweldigende hoeveelheid data ingesamel wat oningewyde navorsers kan oorweldig - veral wanneer die analises en teoriebou begin (Kvale, 1996:85-6). Adler en Adler (1987:80) verwys na navorsers wat so oorweldig is deur honderde velle inligting dat hulle tou opgegooi het. Die navorsing is dus nooit vir akademiese doeleindes op skrif gestel of gepubliseer nie.

Dit is tydrowend en by implikasie duur om bandopnames van onderhoude te transkribeer. Meer nog: dit vereis spesiale kundigheid. Kwalitatiewe analises neem die langste van al die navorsingprosesse en vereis diverse kundigheid. Dit is wenslik dat meer as een kundige en selfs die subjekte by die proses betrokke moet raak om die geldigheid/dialogiese intersubjektiwiteit (kyk die laaste hoofopskrif) van die bevindinge te verhoog (Kvale, 1996:65; Neuman, 2000:124-5).

Daar is reeds genoem dat goeie onderhoudvoering heelwat kundigheid, aanleg en ondervinding verg. Hulp in die vorm van navorsingsassistente vereis dat diesulkes intensiewer opleiding moet ondergaan in teenstelling met diegene wat opgelei moet word vir gestruktureerde onderhoude of vraelyste. In aansluiting by die idee dat kwalitatiewe onderhoudvoering ' $n$ craft is, is dit duidelik dat die oningewyde by die "meester" moet leer - weer eens "n langsame proses. Die gebruik van interpreteerders in kruiskulturele studies maak kwalitatiewe onderhoude ook duur. Benewens die koste en tyd wat hieraan verbonde is, bestaan die moontlikheid dat die interpretasie van die inligting nie noodwendig betroubaar is nie. 


\section{DIE AANNAME DAT TAAL 'N GOEIE AANDUIDER VAN DENKE EN GEDRAG IS}

Kwalitatiewe onderhoude berus op belangstelling in mense se stories. Dit is egter selde moontlik om iemand anders ten volle te begryp omdat jy jouself nie in sy skoene kan plaas nie. Daarom kan mens hoogstens daarna streef om subjekte se gedrag te verstaan en om die subjektiewe begrip wat die persoon aan sy eie gedrag heg, te verwoord (Schutz in Seidman, 1998:3-4). Daar word aangevoer dat taal nie noodwendig a relatively unambiguous pathway to actions, beliefs or actual events is nie (Buckingham, 1991). Subjekte se weergawes van hulle leefwêreld kan inkonsekwent wees, en die stories wat hulle vertel kan dus nie as absolute bewys van hulle denke en begrip aanvaar word nie.

Nie almal het die vermoë om hulle denke en gevoelens te verwoord nie. Daarom behoort subjekte gekies te word wat sover moontlik oor hierdie vermoë beskik en wat genoegsaam geënkultureerd is ten opsigte van die navorser se belangstellingsveld. Dit is algemeen bekend dat verwoorde houdings nie noodwendig 'n goeie aanduider van huidige of toekomstige gedrag is nie (Baron \& Byrne, 1996:140-1). Indien verwoorde houdings en die gedrag wat daaruit voortspruit ondersoek word, is kruisvalidasie by wyse van ander data-insamelingsmetodes belangrik (Fielding, 1993:148). Daar bestaan altyd ' $n$ moontlikheid van leuens tydens ' $n$ onderhoud. Dit kan moedswillig wees om die onderhoud te saboteer, of subjekte kan om persoonlike redes misleidende inligting gee, byvoorbeeld wanneer ' $n$ subjek met ' $n$ laer sosio-ekonomiese status die wenslike wil voorgee (Oakley, 1981:56; Rubin \& Rubin, 1995:171).

Taal is dikwels in kruiskulturele studies ' $\mathrm{n}$ probleem vir beide die onderhoudvoerder en die deelnemer. Vrae moet "korrek" oorgedra word, die deelnemer moet dit "korrek" verstaan, en die inligting moet "korrek" geïnterpreteer word. Daar bestaan nie altyd ekwivalente begrippe in die verskillende tale wat gebruik word nie - te meer wanneer 'n interpreteerder as tussenganger gebruik word (Stewart,1998:25). Fontana en Frey (1994: 367) skryf ... to rely on interpreters (is to) become vulnerable to an added layer of meanings, biases and interpretations that may lead to disastrous misunderstandings. Hierdie aspek kan veral in kruiskulturele studies 'n swak skakel in die navorsingsproses wees.

\section{KWALITATIEWE ONDERHOUDE KAN OP WETENSKAPLIKHEID AANSPRAAK MAAK}

Die kwalitatiewe onderhoud word dikwels afgemaak, veral deur die positiviste, as nie objektief nie en dus nie wetenskaplik nie (Walker, 1985:9-11; Ackroyd \& Hughes, 1981:29; Stewart, 1998:5). Kvale (1996:64$66)$ en Smaling (1989:162) bespreek onder meer konsepte van objektiwiteit en in watter mate inligting uit kwalitatiewe onderhoude daaraan voldoen. Objektiwiteit word gekonseptualiseer as vry van sydigheid, as intersubjektiewe kennis, en as ' $\mathrm{n}$ ware weerspieëling van die aard van die objek.

Objektiwiteit is vry van sydigheid. Dit impliseer dat die kennis betroubaar is, gekontroleer is, sover moontlik vry van navorserseffekte is, en nie deur persoonlike vooroordele en keuses beïnvloed is nie. Kvale (1996:65) skryf dat hierdie begrip good, solid, craftsmanlike research impliseer, wat sistematies deur kruisvalidasie geverifieer is. In beginsel kan die kwalitatiewe onderhoud aan hierdie eis voldoen mits die navorser ' $n$ ware craftsman is en steuringsveranderlikes sover moontlik kon uitskakel (Mouton, 1996:111). ' $n$ Ander belangrike aspek in hierdie verband is die vraag wat die positiviste dikwels stel, naamlik of die navorsing repliseerbaar en die data standhoudend is.

Menslike interaksie is nie repliseerbaar nie en hoogs situasioneel. Kwalitatiewe navorsing met mense is vir die navorser ' $n$ deurlopende leerervaring ten opsigte van die subjekte se kultuur, verhoudings, ervarings en dies meer. Die doel van kwalitatiewe navorsing is om te leer van en insig te bekom in die groepie subjekte wat bestudeer word (Rubin \& Rubin, 1996:2) asook om die inligting van toepassing te maak in soortgelyke gevalle (transferability versus replicability) (Stewart, 1998:12). Buckingham (1991:243) skryf dat navorsers die kompleksiteit van die definisies, begrip en skep van subjekte se eie realiteit moet kan begryp. Hulle moet kan verklaar hoe hierdie begrip van die mikrowêreld in die wyer netwerk van verhoudings in die makrowêreld inskakel. Die navorsingsbevindings kan so as grondslag dien in soortgelyke maar nie noodwendig dieselfde omstandighede nie.

Objektiwiteit is kennis wat intersubjektief getoets en herhaalbaar is. Hoewel sosiale navorsing moeilik herhaal kan word, kan sekere aspekte daarvan intersubjektief geverifieer word. Die rekenkundige intersubjektiwiteit van kwalitatiewe onderhoude kan bepaal word as ' $n$ aantal objektiewe waarnemers voldoende ooreenstemming kan bereik. Dialogiese intersubjektiwiteit word bereik deur rasionele gesprekvoering tydens data-ontleding en interpretasie van die bevindings. Kritiek tussen navorsers asook tussen navorsers en subjekte moet as opbouend aanvaar word om die interpretasie van die bevindings geloofwaardig te maak. Kvale (1996:65) kom tot die slotsom dat objektiwiteit deur goeie navorsingspraktyke bereik kan word, en skryf: With a dialogical conception of intersubjectivity, the interview attains a priviliged position - it involves a conversation and negotiation of meaning between the interviewer and his or her subjects.

Objektiwiteit is 'n weerspieëling van die aard van die navorsingsobjek. Anders gestel beteken dit dat die objek vir homself moet spreek om toereikend vir die navorsingsobjek te kan wees of om die ware aard van die objek bloot te lê. Dit hang saam met die objektiewe keuse/gebruik van 'n metode asook 'n teoretiese begrip van die inhoud of ware aard van die verskynsel. Kvale (1996:66) kom tot die slotsom dat the interview is sensitive to and reflects the nature of 
the object investigated, in the interview conversation the object speaks.

\section{SAMEVATTING}

'n Belangrike sterk punt van onderhoudvoering lê daarin dat dit moontlik dié belangrikste meetinstrument in sosiale navorsing is. Ackroyd en Hughes (1981:70) sê dat ...by using verbal reports offered by respondents, the investigator has access to an almost infinite variety of information that would be virtually impossible to gather by another method. Dit sou egter kortsigtig wees om nie van die beperkings van dié data-insamelingstegniek kennis te neem nie. Navorsers kan nie bekostig om op net een data-insamelingstegniek staat te maak nie. Die beperkings van ' $n$ enkele navorsingsvraag en ' $n$-tegniek of -metode kan egter omskep word in ' $n$ kreatiewe samestelling van navorsingsvrae en gepaste -tegnieke. Dit bied die geleentheid om die geldigheid van die navorsingsbevindings deur kruisvalidasie te verhoog.

\section{LITERATUURVERWYSINGS}

ACKROYD, S \& HUGHES, JA. 1981. Data collection in context. London. Longman.

ADLER, PA \& ADLER, P. 1987. Membership roles in field research. Qualitative Research Methods Volume 6. London. Sage.

BARON, BA \& BYRNE, R. 1996. Social psychology. Boston. Allyn \& Bacon.

BUCKINGHAM, D. 1991. What are words worth? Interpreting children's talk about television. Cultural Studies 5(2):228-245.

DENZIN, NK. 1989. Interpretive interactionism. Newbury Park. Sage.

DEVAULT, M. 1990. Talking and listening from women's standpoint: feminist strategies for interviewing and analysis. Social Problems 37(1):96-116.

FIELDING, N. 1993. Qualitative interviewing. In Gilbert, N. Researching social life. Thousand Oaks, CA. Sage.

FONTANA, A \& FREY, JH. 1994. Interviewing: the art of science. In Denzin, NK \& Lincoln, Y. The handbook of qualitative research. Thousand Oaks. Sage.

HAMMERSLEY, M \& ATKINSON, P. 1995. Ethnography: principles in practice. $2^{\text {nd }}$ ed. London. Routledge.

HUNT, GT \& EADIE, WF. 1987. Communication in interviews. In Hunt, GT \& Eadie, WF. Interviewing: a communication approach. New York. Holt, Rinehart \& Winston.

JONES, S. 1985. Depth interviewing. In Walker, R. Applied qualitative research. Vermont. Gower.

KRUGER, D. $1985 . \quad$ Psychoanalysis, existential phenomenology and qualitative research in psychology. In Focus on quality. Report 21. Institute for Social and Economic Research.

KVALE, S. 1996. An introduction to qualitative research interviewing. London. Sage.

MOUTON, J. 1996. Understanding social research. Pretoria. Van Schaik.

MOUTON, J. 1990. Basiese begrippe: metodologie van die geesteswetenskappe. Pretoria. Raad vir Geesteswetenskaplike Navorsing.

NEUMAN, WL. 2000. Social research methods: qualitative and quantitative approaches. Boston. Allyn \& Bacon.

OAKLEY, A. 1981. Interviewing women: a contradiction in terms. In Roberts, $\mathrm{H}$. Doing feminist research. London. Routledge \& Kegan Paul.

RUBIN, I \& RUBIN, HJ. 1995. Qualitative interviewing: the art of hearing data. London. Sage.

SEIDMAN, I. 1998. Interviewing as qualitative research: a guide for researchers in education and the social siences. New York. Teachers' College Press.

SMALING, A. 1989. Munchhausen-objectivity: a bootstrapconception of objectivity as a methodological norm. In Recent trends in theoretical psychology Volume II. Proceedings of the Third Biennial Conference of the International Society for Theoretical Psychology. New York. Springer.

SMALING, A. 1992. Objectivity, reliability and validity. In Bruinsma, GJN \& Zwanenburg, HM. Methodology for management specialists. Muiderberg. Coutinho.

SMALING, A. 1994. The pragmatic dimension. Paradigmatic and pragmatic aspects of choosing a qualitative or quantitative method. Quality and Quantity 28:233-249.

SPRADLEY, JP. 1979. The ethnographic interview. Fort Worth. Harcourt Brace Jovanovich College.

STEBBINS, RA. 1998. The ethnic outsider: the hurdles of Anglophone field research on North American Francophones. In Grills, S. Doing ethnographic research. London. Sage.

STEWART, A. 1998. The ethnographer's method. Thousand Oaks, CA. Sage.

TAYLOR, SJ \& BOGDAN, R. 1984 . Introduction to qualitative research methods. The search for meanings. $2^{\text {nd }}$ ed. New York. Wiley.

WALCOTT, HF. 1994. Transforming qualitative data. Thousand Oaks, CA. Sage.

WALKER, R. 1985. An introduction to applied qualitative research. In Walker, R. Applied qualitative research. Vermont. Gower. 